\title{
CORRECTION
}

View Article Online

View Journal I View Issue

\section{(D) Check for updates Correction: Electronic and transport properties of Li-doped NiO epitaxial thin films}

Cite this: J. Mater. Chem. C, 2018,

6, 4326

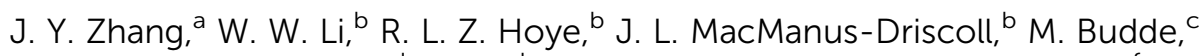 \\ O. Bierwagen, ${ }^{c}$ L. Wang, ${ }^{d}$ Y. Du, ${ }^{d}$ M. J. Wahila, ${ }^{e}$ L. F. J. Piper, ${ }^{e}$ T.-L. Lee, ${ }^{f}$ \\ H. J. Edwards, ${ }^{9}$ V. R. Dhanak ${ }^{g}$ and K. H. L. Zhang*ab
}

DOI: $10.1039 / \mathrm{c} 8 \mathrm{tc} 90056 f$

Correction for 'Electronic and transport properties of Li-doped NiO epitaxial thin films' by J. Y. Zhang et al.,

rsc.li/materials-c

J. Mater. Chem. C, 2018, 6, 2275-2282.

The authors regret the omission of an acknowledgement of funder support, and would like to add the following sentence to the acknowledgements section.

"Transport measurements performed by L. W. and Y. D. were supported by the Early Career Research Program through the U.S. Department of Energy, Office of Basic Energy Sciences."

The Royal Society of Chemistry apologises for these errors and any consequent inconvenience to authors and readers.

\footnotetext{
${ }^{a}$ Department of Chemical and Biochemical Engineering, College of Chemistry and Chemical Engineering, Xiamen University, Xiamen 361005, P. R. China. E-mail: kelvinzhang@xmu.edu.cn

${ }^{b}$ Department of Materials Science \& Metallurgy, University of Cambridge, 27 Charles Babbage Road, Cambridge, CB3 OFS, UK

${ }^{c}$ Paul-Drude-Institut für Festkörperelektronik, Hausvogteiplatz 5-7, DE-10117 Berlin, Germany

${ }^{d}$ Physical Sciences Division, Physical \& Computational Sciences Directorate, Pacific Northwest National Laboratory, Richland, Washington 99352, USA

${ }^{e}$ Materials Science \& Engineering, Binghamton University, Binghamton, New York 13902, USA

${ }^{f}$ Diamond Light Source Ltd., Harwell Science and Innovation Campus, Didcot, OX11 ODE, UK

${ }^{g}$ Department of Physics, University of Liverpool, Liverpool L69 3BX, UK
} 